\title{
LA ACCIÓN EXTERIOR DE BRASIL A EXAMEN. \\ ENTREVISTA A BRUNO AYLLÓN , ESPECIALISTA \\ EN EL ESTUDIO DE LAS RELACIONES INTERNACIONALES BRASILEÑAS
}

Entrevista con el politólogo y especialista en las relaciones España-Brasil, Bruno Ayllón Pino, autor del libro Las relaciones hispanobrasileñas: de la mutua irrelevancia a la asociación estratégica (19452005), en la que se abordan cuestiones como la trayectoria investigadora, el papel que juega Brasil en el concierto internacional, el estado de las relaciones entre Brasil y España, la acción cultural brasileña, la cooperación Sur-Sur y el presente y futuro de todos estos campos de estudios.

\section{José Manuel Santos Pérez}

Profesor titular de Historia de América del Departamento de Historia Medieval, Moderna y Contemporánea de la USAL. Codirector de la REB.

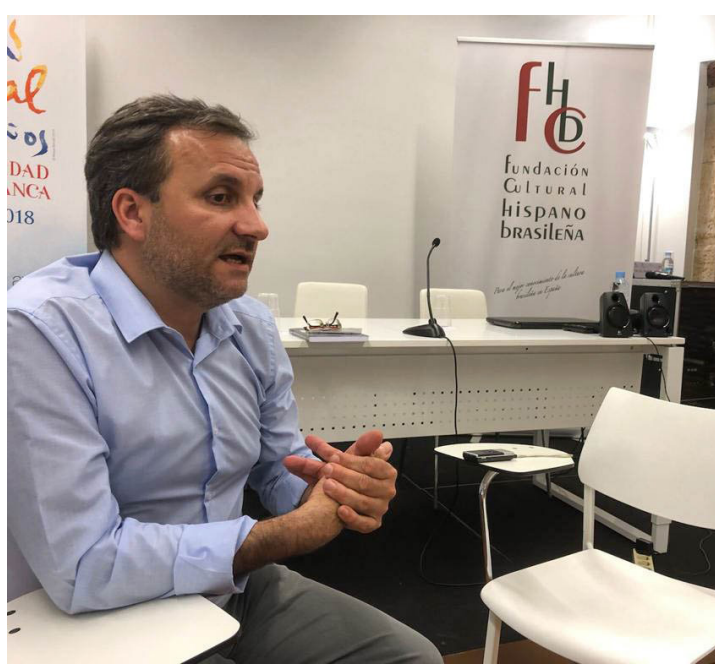

Bruno Ayllón Pino (Salamanca, 2019).

Foto: Centro de Estudios Brasileños.
Elisa Tavares Duarte

Editora de la REB. 
La historia del brasileñismo en España en los últimos veinte años no se entendería sin Bruno Ayllón Pino (Madrid, 1968) politólogo y especialista en las relaciones España-Brasil. Con su tesis doctoral de 2004 en la Universidad Complutense (publicada por Ediciones Universidad de Salamanca, en 2007) abrió un amplio campo de investigación que hoy se transita con más elementos de juicio gracias a su trabajo pionero. Su formación se completó con un postdoctorado en la USP en los años 2005-2006, financiado por el MEC y desarrollando un proyecto sobre relaciones UE-Mercosur. Desde aquel momento y hasta la actualidad ha seguido trabajando intensamente en temas diversos, que abarcan tanto la llamada Asociación Estratégica que España y Brasil establecieron en los inicios de los 2000, como, y, sobre todo, las relaciones entre países del Sur y los programas de Desarrollo Sur-Sur, en los que el doctor Ayllón es una figura destacada. Su amplísimo conocimiento de la política, la sociedad y la historia de Brasil, junto con su destacada labor académica, han hecho imprescindible su presencia y participación en foros como los encuentros de brasileñistas españoles (Salamanca en 2005, Madrid en 2006, Salamanca en 2008), y le sitúan en una posición de gran influencia en este campo de estudios. La entrevista se realizó en el Centro de Estudios Brasileños de Salamanca, aprovechando la estancia de Bruno Ayllón para impartir el curso Las relaciones entre España y Brasil en los últimos 25 años. Historia y perspectivas. En ella se abordan cuestiones como la trayectoria investigadora, el papel que juega Brasil en el concierto internacional, el estado de las relaciones entre Brasil y España, la acción cultural brasileña, la cooperación Sur-Sur y el presente y futuro de todos estos campos de estudios.

\section{Trayectoria investigadora}

Elisa Tavares Duarte: Doctor Ayllón, buenas tardes, gracias por concedernos esta entrevista. Queríamos comenzar comentando algunos aspectos de tu trayectoria investigadora. Tu tesis doctoral de 2004, Las relaciones entre Brasil y España ponderadas desde la perspectiva desde la política exterior brasileña (1979-2000), venía a cubrir una laguna en la historiografía de las relaciones entre España y Brasil. ¿Cómo fue el acercamiento al tema?

Bruno Ayllón Pino: Eso fue hace mucho tiempo. Era un momento en el que se hacían necesarias explicaciones de carácter histórico, pero también de contenido político, económico y sociológico, para explicar la dinámica de intensificación de las relaciones entre los dos países, entre las dos sociedades. En los años en los que trabajé en la tesis, en realidad, había que recomponer, inventarse las piezas de un puzzle, que eran las relaciones entre España y Brasil, que no estaban o no existían, o estaban muy dispersas. Es cierto que había alguna literatura y tesis de doctorado que avanzaban en algunos temas en concreto, desde miradas sectoriales, por ejemplo, el campo de las migraciones, de relaciones económicas, pero faltaba una versión más holística y abarcadora de esa complejidad de las relaciones entre España y Brasil. Quizás, la mayor contribución fue hacer un trabajo casi de Paleontología, en el sentido de ir descubriendo esas piezas e ir dándole forma, intentar ver si ensamblaban unas con otras. Para ello, fue fundamental la investigación en los archivos históricos de Itamaraty, el Ministerio de Relaciones Exteriores de Brasil, en Río de Janeiro y Brasilia, y en la medida de lo posible, con las limitaciones que había por cuestiones legales en cuanto a los documentos a los que se podía acceder y consultar, poder cotejar esa información con la existente en el Palacio de Santa Cruz, en el Archivo del Ministerio de Asuntos Exteriores de España. No fue un trabajo fácil. Fue complicado porque había que intentar darle un sentido, había que construir un sentido para informaciones que, a veces, estaban desconectadas; había que componer ese lienzo y solamente teníamos algunos elementos. Creo que fue muy importante en ese proceso la interacción con otras personas que también estudiaban Brasil desde otras disciplinas. El contacto con algunas
PALABRAS CLAVE Bruno Ayllón Pino; Relaciones Internacionales; Brasil; España.

PALAVRAS-CHAVE Bruno Ayllón Pino; Relações Internacionais; Brasil; Espanha.

KEYWORDS

Bruno Ayllón Pino; International relations; Brazil; Spain. 
personas que, en momentos no muy lejanos, habían sido protagonistas en las relaciones entre España y Brasil. Recibí el apoyo de la Embajada de España en Brasil y de la Embajada de Brasil en España y, por supuesto, las contribuciones del Centro de Estudios Brasileños y del que entonces era su director, José Manuel Santos, así como de aquel incipiente grupo de brasileñistas, que intentábamos aglutinarnos y poder intercambiar esos pedazos de conocimiento que teníamos, que además fue un elemento que también sirvió como argamasa de esas piezas del puzzle, que muchas veces no encajaban. Siempre se dice que las tesis son pecado de juventud, y creo que esa tesis también fue un pecado de juventud. Hoy en día probablemente lo abordaría desde perspectivas diferentes e intentaría recurrir a fuentes que no consulté en su momento. Creo que las tesis no son un fin, son un medio y son el inicio de una línea de investigación que, en mi caso, he continuado profundizando.

ETD: Tres años después de la tesis, publicas un libro por Ediciones Universidad de Salamanca (Ayllón, 2007), con una diferencia: en el libro tenías un recorte cronológico más amplio. ¿En qué avanzaste con respecto a la tesis en la publicación de este libro?

Bruno Ayllón Pino: Quizás, más que avanzar, prescindo de cosas, ya que evidentemente a la hora de trasladar una tesis a un libro, normalmente, le quitamos toda la parte metodológica, todas las cuestiones teóricas y conceptuales y dejamos un libro que sea más asequible a un lector que no tiene porqué ser especializado en el campo de las relaciones entre España y Brasil. Luego, creo recordar que también el libro que se publicó en Salamanca estaba despojado de algunos capítulos del ámbito multilateral, de cómo las relaciones entre España y Brasil se habían materializado en diferentes momentos históricos en organismos multilaterales. También hubo una actualización a lo que era la realidad del Plan de Asociación Estratégica de 2003. Cuando hice la tesis, este plan todavía estaba en formulación, y cuando se publica el libro ya se había avanzado un poco en lo que era el plan de trabajo de esa Asociación Estratégica. Esas son las diferencias básicas entre las dos obras.

ETD: ¿En qué ha avanzado la historiografía con respecto a las relaciones entre España y Brasil en estos últimos 15 años?

Bruno Ayllón Pino: Bueno, debo decir que, aunque he seguido siempre el tema de las relaciones BrasilEspaña por diferentes motivos profesionales, he tenido que desviarme a otros campos de actuación y a otras líneas investigación. De modo que no me siento con autoridad como para decir qué se ha hecho y qué no se ha hecho. De lo que sé, creo que ha habido un avance importante en cuanto a los trabajos de investigación acerca de la presencia de españoles en Brasil con algunas tesis que fueron presentadas por estudiantes del Departamento de Historia Medieval, Moderna y Contemporánea y del Centro de Estudios Brasileños, dirigidas por José Manuel Santos (Gambi, 2008; Zamorano, 2010). También ha habido un avance importante desde la otra mirada, que son tesis de brasileños en España que han investigado sobre, digamos, esos flujos migratorios de Brasil en España, destacando los trabajos publicados en la Universidad de Barcelona, un hecho impulsado también por la fuerte presencia de brasileños en aquella ciudad. Al mismo tiempo, ha habido un avance en algunas temáticas delicadas, pero que también reflejan cómo la relación bilateral se ha ido haciendo compleja y ha tenido que enfrentar los desafíos que esa propia intensidad de las relaciones ha ido manifestando, por ejemplo, el tema de la trata de personas con fines de explotación sexual, que ha sido una línea de trabajo que se ha desarrollado aquí en España, centrándose específicamente en el caso de mujeres brasileñas y de transexuales en el campo de la prostitución y todo lo que implican esas redes. En Brasil también se ha avanzado en cuanto a la relación entre España y Brasil, en la línea de lo que yo había hecho, pero quizás tomando algún periodo histórico que yo no trabajé y profundizando, también, con el acceso a nuevas fuentes. Esa fue una tarea realizada por la doctora Ismara Izepe de Souza, profesora de la Universidad Federal del Estado de São Paulo (Unifesp, Brasil), que empezó trabajando los temas migratorios de españoles en Brasil con una mirada centrada en cómo esos emigrantes republicanos, anarquistas o comunistas eran perseguidos por la policía política de Getúlio Vargas. Lo que ella hace en la tesis de doctorado es un trabajo muy meritorio que se concentra en la época de la Guerra Civil española y en las relaciones de los gobiernos Vargas y la España franquista, y finalmente en la visita de Juscelino Kubitschek (1956-1961) a España en 1956, y lo que significó para el desarrollo de las relaciones 
bilaterales en los siguientes meses. Si tuviese que hacer un balance diría, quizás con un poco de pesar, que no ha habido todo el interés o la motivación para que haya habido más tesis y publicaciones, por lo menos en el periodo que yo trabajo que es un periodo contemporáneo, actual. Por supuesto que en el campo de la Historia colonial o de otros ámbitos sí que ha habido mucho más avance en ese tema, pero en cuanto a las relaciones políticas entre España y Brasil en la segunda mitad del siglo XX y todo este siglo XXI, creo que ha habido una divulgación fuerte en medios de comunicación, incluso artículos publicados en esta Revista de Estudios Brasileños, pero creo que el panorama es todavía muy restringido. Pienso que no ha traspasado algunas barreras y que eso también es reflejo de que, quizás, las relaciones bilaterales, a pesar de ser tan buenas en los últimos años en líneas generales, no han sido motivo suficiente como objeto de estudio para que se pudiera profundizar en la temática. Quizás en el conflicto que hubo entre 2008 y 2012, por la cuestión de los brasileños no admitidos en los aeropuertos españoles, dado el papel de España como puerta a la Unión Europea, sí que ha habido algunos análisis más en profundidad, pero, en líneas generales, aunque suene a tópico, queda mucho por trabajar. Además, creo que esa es una tarea donde tendremos que hacer una reflexión sobre si hemos conseguido, personal e institucionalmente, a través de las instituciones que apoyan los estudios sobre Brasil en España, como la Embajada de Brasil o la Fundación Cultural HispanoBrasileña, asegurar en el futuro nuevas generaciones de brasileñistas españoles. Muchas veces tenemos estudiantes de doctorado que han hecho su tesis sobre Brasil, pero luego abandonan el tema, y en ese sentido una radiografía de la situación del brasileñismo actual en España tendría una mirada muy crítica y, probablemente, diría que hace 10-14 años había mucha más cohesión. Hoy en día, creo que el brasileñismo en España está muy disperso y muy desconectado, centrado en las redes personales que tienen los investigadores. Hace falta un apoyo institucional mucho más decidido, que no sea puntual, espasmódico, y no esté al albur de las coyunturas. Igualmente, que entienda cuál es la misión del académico, que debe tener una mirada crítica hacia la realidad y hacia las relaciones entre España y Brasil. En aquellas situaciones que entienda que las cosas no van bien, criticarlas; y esto, evidentemente, desde algunas instituciones no siempre se entiende como algo positivo, porque hay una intencionalidad política en alguna de ellas. No lo critico, es la naturaleza de cada cosa, pero creo que se debe encontrar ese punto de convergencia donde podamos cada uno cumplir nuestros intereses y avanzar en la agenda común, que es la del conocimiento mutuo entre los dos países, entre las dos sociedades.

ETD: Has hablado sobre fuentes, las que investigaste para la tesis, y de que, a lo mejor, hoy consultarías otras. En el caso de una persona, del doctorando o investigador que esté empezando y tenga interés en el tema de las relaciones entre España y Brasil, ¿qué tipo de fuentes o documentación podría consultar desde aquí sin tener que ir a Brasil? ¿En términos generales, qué es lo que está disponible y de fácil acceso?

Bruno Ayllón Pino: Yo creo que eso sería una tarea interesante por realizar: el facilitar el trabajo que otros tuvimos que hacer, que fue exactamente recopilar toda la bibliografía existente en el tema de las relaciones entre España y Brasil desde la época de la Unión Ibérica, e ir pescando por aquí y por allá lo que había. En mi tesis hay mucha bibliografía de lo que yo encontré en su momento, pero seguro que hay cosas por incluir. Un catálogo bibliográfico o alguna publicación que fuera un análisis de fuentes sobre las relaciones entre Brasil y España sería quizás un documento que pudiera apoyar a estos investigadores (González, 2002). Por supuesto, más allá de lo que son fuentes directas que pueden estar en la documentación diplomática, que no deja de ser una documentación problemática en cuanto a forma de acceso, plazos, lo que se puede consultar en función de la clasificación que tengan los documentos, el propio estado de conservación de los mismos en función de los archivos, la lentitud exasperante del Archivo del Ministerio de Asuntos Exteriores español, al menos a inicios del año 2000... Sobre eso habría mucho que hablar, pero evidentemente hice el trabajo de campo de mi tesis hace casi veinte años, e imagino que ahora se podrá acceder a series documentales que en aquel momento no estaban disponibles. Yo no consulté el Archivo General de la Administración de Alcalá de Henares, y ahí está toda la documentación referente a los consulados, que fue la base que utilizó Ismar Izepe de Souza. Creo que es importante ir a los archivos de la Fundación Getúlio Vargas, examinar también la documentación personal de algunas figuras relevantes en la relación bilateral, como por ejemplo los fondos de la Fundación Francisco Franco, etc. Es decir, intentar tirar por ahí algunas líneas. Yo creo que eso sería un trabajo bonito incluso para hacer un seminario donde nos reuniéramos un grupo de personas que trabajamos sobre la relación España-Brasil y planteásemos líneas de intercambio, 
de fuentes, sobre qué podemos encontrar, qué temas no se han tratado... y a partir de esa tormenta de ideas, que salgan cuestiones interesantes, porque me parece que es central la cuestión de que haya más fuentes, cómo de disponibles están, preguntas que hay que responder en un trabajo colectivo, sumando el conocimiento que todos tenemos, e intentar tener un documento que pueda ser de utilidad para las investigaciones presentes y futuras.

\section{Relaciones internacionales entre España y Brasil}

José Manuel Santos Pérez: ¿Cuál ha sido el papel, en general, de Brasil en las relaciones internacionales? ¿Y cómo valorarías esta cuestión en el pasado y qué perspectivas se apuntan? Evidentemente, ahora la cuestión es si se vislumbran cambios importantes al respecto de las relaciones internacionales de Brasil con el gobierno Bolsonaro, dado que han anunciado que están en contra de la globalización y a favor del proteccionismo, "primero Brasil y después lo demás"... ¿Crees realmente que la línea trazada por Brasil en el siglo XX podría cambiar en este momento?

Bruno Ayllón Pino: Aunque tiene rasgos de continuidad, la política exterior siempre tiene cambios dentro de lo que es la tradición diplomática de Brasil. El gobierno de Fernando Henrique Cardoso (FHC, presidente entre 1995-2002) hizo una apuesta fuerte por la inserción en la globalización, contemplada un poco de manera naif, como el sol que alumbra todo y del que todos se benefician. Una visión muy fundamentada en la teoría liberal, que era la que alimentaba la política exterior del gobierno FHC. Eso cambia con los gobiernos Lula en el sentido de plantear una política exterior mucho más realista, de diversificación de las relaciones del país, no haciéndolas exclusivamente dependientes de los países del Norte. En ese momento, la constitución de ese eje de Sur-Sur, en la política exterior de Brasil, fue una aportación importante del país ya que hizo una lectura, en mi opinión, bastante acertada de las transformaciones que se estaban operando en el sistema internacional, leyendo el surgimiento de nuevos poderes, el desplazamiento del eje de la riqueza del poder del Oeste hacia el Este, en concreto hacia el Pacífico, y el desplazamiento de ese eje de poder y de la riqueza hacia China y otros polos emergentes. En este sentido, Brasil interpretó que podía ser uno de esos polos emergentes en América Latina, y de esta manera responder a lo que yo creo que fue el gran proyecto geopolítico del gobierno Lula, tal vez de autoría del canciller Celso Amorim, que fue la constitución de un mundo multipolar frente a un mundo bipolar que tuvimos durante la Guerra Fría, y un mundo de polaridades indefinidas en el cual no estaba muy clara cuál era la nueva configuración de poder del mundo, si sería unipolar con Estados Unidos como potencia solitaria, si sería un G2 con Estados Unidos y China, o un G0 donde ni China ni Estados Unidos conseguirían controlar el tablero mundial. Creo que esa lectura del mundo multipolar fue una gran aportación de Brasil, no solo en la teoría sino también en la práctica, con la generación de coaliciones multilaterales con países emergentes, llámese BRICS', llámese Foro IBAS ${ }^{2}, \mathrm{CELAC}^{3}$, UNASUR ${ }^{4}$, u otra serie de iniciativas que transmitían el mensaje de América del Sur para los sur americanos, América Latina para los latinoamericanos y caribeños, excluyendo a los Estados Unidos y reinsertando en la jugada a Cuba que, me parece, era importante en la lectura de las relaciones regionales que tenían esta deficiencia desde los años 1960-62, cuando la isla caribeña fue excluida del sistema interamericano. Además, creo que fue una visión que apostó fuertemente por África, y eso significó la recuperación de lo que ya había sido un experimento del gobierno de João Goulart (19611964), que fue la política exterior independiente, intentando identificar en África un espacio de acción de Brasil, no solamente desde la perspectiva sentimental por los vínculos que unen África con Brasil debido a la cuestión de la esclavitud, sino que en el caso del gobierno Lula es un vínculo pragmático, donde se identifican oportunidades de negocio, donde hay oportunidad de cooperación técnica, de entrada de las empresas brasileñas en el mercado africano, y donde, además, encontramos la recuperación de una lectura desde una perspectiva constructivista, de identidades. Es decir, la idea del rescate de la deuda histórica que Brasil tiene con África. El momento simbólico fue la visita de Lula a Benín, al famoso "Portal sin retorno", de donde salían los esclavos. Se conjugan muy bien, por una parte, los elementos del poder duro de Brasil, que son pocos en realidad, pero sobre todo se ponen en valor los elementos del poder blando del país, la imagen y la proyección exterior a partir de las conquistas en materia social, el hecho de que un obrero llegue a la presidencia de la Republica... En fin, todos estos elementos los ha sabido jugar 
bien Brasil. Pero al mismo tiempo, juegan al juego duro de las relaciones internacionales, hasta el momento que toca un cable de alta tensión cuando planteó el acuerdo con Irán, la negociación turco-brasileña para toda la cuestión del enriquecimiento de uranio. Ahí saltaron las alarmas. Se vino a decir: ustedes se están metiendo en un tema que no les compete. En ese momento hubo un pequeño resbalón, pero evidentemente son tiempos que, cuando uno vuelve la vista atrás, se ve que Brasil era un país protagonista, portada de revistas internacionales, parecían días de vino y rosas... felicidad. Pero llegó la crisis, la crisis política, económica, y hubo una pérdida de imagen de Brasil en el mundo, que fue también reflejo de la pérdida del peso que el propio país había experimentado desde la perspectiva económica, del prestigio; una imagen de un país arrasado por la corrupción, de un gigante con pies de barro donde la cuestión social todavía limitaba el que Brasil proyectara poder e influencia hacia el exterior. Creo que el panorama actual es más preocupante, ya que esa pérdida de imagen, que parece con el gobierno Bolsonaro más un desvarío, golpea la imagen actual de Brasil, con el alineamiento automático con la administración Trump o las relaciones con el gobierno Orban en Hungría. Lo más preocupante es que, a día de hoy, todavía no conocemos cuáles son los objetivos de la política exterior de Brasil. Este gobierno [de Bolsonaro] llegó al poder predicando que sería un gobierno sin ideología, y lo que vemos es exactamente la ideología galopando a caballo en este gobierno, y especialmente en la cancillería, donde tanto se criticaba la acción del canciller Amorim. No hay una idea, no hay un objetivo, unas metas, una priorización geográfica de cuáles son los intereses de Brasil en el mundo; no hay una lectura de este gobierno sobre en qué foros actuar. Es una improvisación a partir de un discurso mesiánico en el cual el canciller Araújo viene a decir que Brasil es el país elegido por Dios para proclamar el nuevo evangelio del gobierno Bolsonaro. Evidentemente esto magulla y estropea la imagen de Brasil en muchos países, por lo menos haciendo una lectura desde el ámbito europeo.

JMSP: Brasil es un gigante económico, nadie lo duda. Sin embargo, esta fuerza económica no se refleja en su influencia internacional. ¿A qué crees que se debe esto?

Bruno Ayllón Pino: Bueno, lo que dices me recuerda a la frase atribuida a Jacques Delors sobre la Unión Europea de los años 1980: "un gigante económico, un enano político y un gusano militar". En el caso de Brasil, digamos, ese gigantismo económico hay que matizarlo mucho, creo. El indicador central que expresa el peso económico de un país no es el PIB bruto sino el PIB per cápita, que es el que señala la distribución de la riqueza entre la población. Evidentemente, si atendemos a las cifras del PIB, Brasil está entre los diez mayores del mundo, pero si vemos la renta per cápita del país, encontramos un perfil de renta media, y tomando el Índice de Desarrollo Humano (IDH) de las Naciones Unidas, Brasil aparece en el número 80-85 de un total de 190 países. Hay, por tanto, una lectura un poco deslumbrada de los BRICS en el sentido de que, sí, son grandes economías, pero incluso China tiene una renta per cápita ridícula, aparece en el número 90 en el IDH, la India en el 120. Mientras que Argentina, Chile o Uruguay están en el puesto 40-45-47 en ese índice en el que Brasil está en el 85. Sin embargo, no hablamos de Argentina, Uruguay o Chile, porque estamos deslumbrados por el ascenso brasileño. Creo que los medios de comunicación, los intereses económicos, jugaron un papel muy importante. El propio gobierno brasileño quiso jugar esa baza de "gigante pela própria natureza", el famoso verso del himno de Brasil, que a los brasileños les gusta mucho, con esa idea de "somos grandes", ese ufanismo tan típico brasileño. Esto se ha venido abajo, ya que, sin reformas estructurales, sin la reforma política, el país no avanza. Esto lo escribí en algún momento y no sentó muy bien. Cuando se vino a presentar el Programa de Aceleración del Crecimiento (PAC) durante el primer gobierno de Dilma Rousseff lo dije claramente, ¿dónde están las reformas estructurales? En este sentido, los vicios de la vieja política brasileña y la promiscuidad del capitalismo brasileño con la clase política, son históricos, y de ellos se habla muy poco. Un modelo de capitalismo tupiniquín donde esa promiscuidad del poder público y prácticas capitalistas son tremendamente perversas, y esto ha llevado al agujero al gobierno del Partido dos Trabalhadores (PT), en mi opinión. Eso y las alianzas espurias con grupos políticos de poca confiabilidad. Entonces, ¿es un gigante económico? Sí, relativamente. ¿Puede proyectar poder hacia el exterior? Creo que lamentablemente ni siquiera hacia América Latina. Hay una serie de artículos de Andrés Malamud, profesor de la Universidad de Lisboa, en los que dice que Brasil es un líder sin seguidores (Malamud, 2011). Es decir, aspira a ser líder en América Latina, pero sin embargo no tiene seguidores. Y desde luego con el gobierno Bolsonaro mucho menos. Ni siquiera el que podía haber sido su aliado regional, el entonces presidente Macri, fue a la toma de posesión, y además perdió 
las elecciones en Argentina. ¿Cuáles son los apoyos de Bolsonaro en América Latina? Y América Latina es lo más próximo que tiene Brasil. Y no digamos en África o Asia, donde las primeras peleas que tuvo el actual gobierno fueron con China. Si tienes un superávit comercial con China y te va bien con ellos, ¿por qué te metes en campaña electoral con ellos y dices que los chinos están comprando Brasil? Generas una controversia diplomática antes de llegar al poder, y luego la ratificas con el canciller, que vuelve a criticar a China. Hay que tener cuidado con meterse con China ya que hay en juego mucho dinero, inversiones y los puestos de trabajo de muchos brasileños. Creo que hay mucha desorientación y nos dejamos deslumbrar por ese ascenso de Brasil, pero no hubo reformas estructurales. Es cierto que hubo alguna distribución de la riqueza, pero si vemos los índices que miden la concentración del ingreso, sean el Gini, el Palma, o el Theil, todos ellos nos dicen que la desigualdad no se redujo a la misma velocidad. Y, sobre todo, que no era sostenible ese tipo de políticas, ya que se optó, durante el gobierno Lula, por hacer una inclusión a través del consumo y no por una inclusión a través de la capacitación y empoderamiento de los ciudadanos. Se preferían ciudadanos mendigos a ciudadanos activos; bueno, por ahí yo creo que hay líneas políticas en Brasil que están trabajando con esta propuesta de futuro.

JMSP: Vamos a la cuestión concreta de las relaciones España-Brasil. Hay una frase famosa que tú acuñaste y que es la del propio título del libro, "de la mutua irrelevancia a la asociación estratégica", como tú defines el transcurso histórico de estas relaciones. ¿Cómo se produce, cuándo y cuáles son las características de este salto cualitativo tan llamativo que tú has señalado en esta cuestión?

Bruno Ayllón Pino: Es un proceso gradual, como todos los procesos históricos, salvo aquellos de corte revolucionario. Aquí, lo que hay es una aceleración en un momento dado, a partir de la confluencia de una serie de factores que se fueron sedimentando en décadas anteriores. Si tomamos 1995 como una fecha importante que señala la llegada de las primeras inversiones españolas fuertes a Brasil, entonces tenemos unos 2425 años que son los que hemos intentado analizar en el seminario que hemos realizado estos días en el Centro de Estudios Brasileños. Son factores de tipo político: teníamos unas relaciones que eran básicamente insustanciales, sin grandes conflictos, pero también sin grandes interdependencias ni conexiones entre ambos países, una gestión rutinaria de los asuntos consulares y comerciales, y una buena sintonía política en general. En determinados momentos del siglo XX esa especie de inercia, de parsimonia, se rompe con algunos episodios de ámbito multilateral como la cuestión española en Naciones Unidas en 1946 y la ruptura de las relaciones diplomáticas con muchos países, entre ellos Brasil, periodo que dura cuatro años. Luego, tenemos una intensificación de las relaciones en el contexto de la España franquista con su política de hispanidad hacia América Latina y el trato diferenciado que se intentó imprimir a la relación con Brasil. Y, después, tenemos la estrategia de convergencia desarrollista entre las dictaduras militares del general Franco y los generales militares brasileños de los años 1960. Faltaba un elemento decisivo, que creo que es el primer factor fundamental para explicar ese proceso de intensificación y fortalecimiento de la asociación hasta llegar a algún tipo de relación estratégica. En primer lugar, la redemocratización que se dio primero en España y en Brasil después, en la que el proceso español fue un espejo donde Brasil intentó mirarse. Hubo una fuerte interrelación política que, quizás, tiene un momento simbólico en la visita de Adolfo Suarez a Brasil en 1979, la primera que realiza un presidente del gobierno. Posteriormente, João Batista Figueiredo también visitó España para retribuir esa visita, y luego las visitas fueron casi rutina por parte de los gobiernos socialistas, al más alto nivel con el rey Juan Carlos, ya que España ya quería incluir a Brasil en su nueva política iberoamericana, integrando a Brasil en las conferencias iberoamericanas, lo que logró finalmente cuando, en 1991, consigue cerrar un trío de líderes que son España, México y Brasil, sin los cuales esa política iberoamericana del gobierno socialista de la España democrática no habría sido posible. La primera cumbre se celebró en Guadalajara, México, en 1991; la segunda, en 1992, en España, en Madrid; y la tercera se celebró en Salvador de Bahía, Brasil, con el gobierno Collor. Creo que ese fue un momento importante para entender cómo la buena sintonía política, la vuelta de sociedades democráticas y un proyecto multilateral en el espacio iberoamericano donde Brasil participa con alguna reticencia, hay que decirlo, pero que participa finalmente, son piedras que van pavimentando la carretera de las relaciones hispano-brasileñas hasta que se pudo convertir en una "autovía" y luego en una "autopista". 
El segundo proceso es el de los fenómenos de integración regional que se producen, por un lado, en Brasil, con la creación del Mercosur en 1991, y todo el proceso que lleva a España a ingresar en la Comunidad Económica Europea en 1986, y luego a partir de 1995, con la firma del Acuerdo Marco de Cooperación Interregional entre la Unión Europea y Mercosur. La agenda exclusivamente bilateral se enriquece, se diversifica, ampliando esa dimensión que es el papel de Brasil como articulador entre Mercosur y la Unión Europea y, por otra parte, el papel que España y Portugal tienen como articuladores de la relación de la Unión Europea con Mercosur vía Brasil. Creo que ese juego funciona relativamente bien y es un factor para tener en cuenta. El tercer factor es, sin duda, el económico. La llegada de las inversiones españolas, como consecuencia de los cambios que experimenta Brasil en el proceso de estabilización económica, con el Plan Real, permitió el desembarco de las grandes empresas españolas que previamente venían de un proceso de maduración, de privatización, de alguna experiencia internacional, pero que se encuentran con un mercado europeo saturado de inversiones, resultando así que el espacio natural de actuación internacional para esas empresas es América Latina. Dentro de América Latina, Brasil desempeña un papel fundamental. Hay también un contexto de racionalidad económica, que tiene que ver con el tamaño del mercado brasileño. En aquel momento debían de ser 170 millones de habitantes y evidentemente eso garantizaba la entrada en un gran mercado, que además contaba en la época con una moneda fuerte. De esta manera la repatriación de dividendos suponía un buen negocio. Además, muchas de las empresas públicas estaban siendo privatizadas por el gobierno FHC a precio de saldo, con lo cual el negocio era redondo. Sobre esto hay mucha controversia y muchos estudios, pero a partir de entonces la relación estuvo pautada por lo económico, incluso hasta hoy en día, aunque en tiempos del gobierno Zapatero y del gobierno Lula se intentara imprimir un cuño más social a la relación estratégica. Por lo tanto, el tema económico es central y las demandas que hay entre las dos partes para incrementar el comercio, para hacerlo más equilibrado y diversificar las pautas de exportaciones, en el caso de Brasil, son temas cotidianos, que además se apoyan en una serie de relaciones personales que son muy fuertes entre los sectores empresariales de España y Brasil y otros sectores del ámbito académico, artístico, etc.

JMSP: Hay un aspecto sobre el que me gustaría oírte: me llama mucho la atención, desde una perspectiva histórica, y también en el desarrollo de estas relaciones de Brasil con España, eso que tú has llamado "la hispanidad", muy marcada en tiempos de Franco. Y es que España no puede negar su pasado y hasta donde puede lo aprovecha, en la medida que tiene unas relaciones privilegiadas con los países de habla hispana. Claro, Brasil no es un país de habla hispana, entonces en esta relación curiosa que España establece con los países hispanoamericanos, así llamados antes, que han derivado en iberoamericanos, imagino que por mor de querer incluir a Brasil...

Bruno Ayllón Pino: No solamente por incluir a Brasil, ya que saben que si no incluyen a Brasil cualquier intento de política hispanoamericana está abocado al fracaso.

JMSP: Efectivamente. En la propia relación internacional de España ha habido un esfuerzo, creo entender que es así, por reformular las relaciones con el conjunto de países de América Latina. Entonces, la cuestión que te planteo es que en esta "reformulación" de las relaciones de España con América Latina hay un tercer actor que es Portugal, que ha tenido igual que España sus relaciones ciclotímicas con Brasil, es decir han estado a la greña, después han estado muy unidos, e incluso hubo a finales del siglo XIX un "panlusitanismo", como hubo un "pananglicismo". Creo que en la medida en que Brasil y España se acercaron, siempre Portugal intentó de alguna manera mediar en esto; siempre me ha parecido que, desde Portugal, se lanzaba una idea de que había que tener cuidado con las relaciones entre España y Brasil, que siempre habría de contar con ellos. Por otro lado, esto no podría ser si no fuera por un hecho consustancial a la propia identidad de Brasil como nación, una identidad que Buarque de Holanda llamaba identidad "neoportuguesa" de Brasil, que se construyó durante el siglo XIX, fundamentalmente con Varnhagen, y que el historiador creía que se debía desechar para crear una nueva identidad de Brasil. Aunque esto fuera decimonónico, es evidente, y llama la atención en Brasil, el carácter muy portugués que tiene la identidad brasileña, incluso en los tiempos que corren, al mismo tiempo que Brasil ha intentado construir su propia identidad de país. ¿Cómo ves este triángulo, a veces me parece que imposible, entre Brasil-España-Portugal, y cómo se ha desarrollado una política de relaciones propias entre España y Brasil que antes era casi imposible porque Portugal casi no dejaba realizarla? ¿Has visto algo de esto? 
Bruno Ayllón Pino: Hay una frase famosa de Mario Benedetti que dice que "en la vida hay que evitar círculos viciosos, mentes cuadradas y triángulos amorosos". Y el triángulo España-Portugal-Brasil desde luego nunca fue amoroso. Yo diría que fue un triángulo lleno de susceptibilidades, de cuidados, de salvaguardas, ya que por lo menos en la época franquista, la relación con Portugal era más importante que la relación con Brasil. Es decir, cualquier acción de España en Brasil no podía interferir o generar susceptibilidades en Portugal. Eso fue, además, una línea de acción diplomática que mantuvieron los embajadores de España en Brasil durante la época franquista, especialmente Tomás Suñer y Ferrer, en los años 50. Yo no soy capaz de entrar en las profundidades de Sérgio Buarque de Holanda, pero digamos que mirando un poco más a la época contemporánea esa cuestión de la identidad, creo que se relativiza mucho en la medida en que la globalización, por una parte, obliga a los países a una serie de dinámicas, y una consecuencia de esto es que el propio hecho de que España y Portugal entrasen en la Unión Europea contribuyó a que esas desconfianzas entre ambos se diluyesen. También porque quedó muy patente que, en la perspectiva comparativa, y económicamente, el peso español en América Latina fue mucho mayor que el peso económico que tuvo Portugal, que nunca lo tuvo, en realidad. Cuando hay dinero esas palabras hablan más fuerte que las cuestiones de identidad. Yo creo que ahí España hizo bien la jugada, le salió bien. Portugal intentó hacerlo en Brasil y no le fue muy bien. Estoy pensando en el banco Espírito Santo, algunas inversiones que no le fueron bien a Portugal, pero es cierto que ese ascendente moral, histórico, creo que se fue diluyendo, tanto que el tratado de amistad bilateral entre Brasil y Portugal de 1953, si no recuerdo mal, hizo que fuera perdiendo vigencia a medida que España y Portugal, a finales de los 1970 empiezan su proceso de acercamiento a la Unión Europea y van de la mano, ya que están en el mismo "paquete". A la vez, pienso que también hay que tener en cuenta una realidad importante, que es el peso de España en Portugal, económicamente inmenso. Portugal entiende que no puede enemistarse económicamente con España, lo cual podemos decir que deja a Portugal en una doble pinza donde no tiene mucho margen de maniobra. Sin embargo, Portugal ha acompañado y ha sido honesto y caballeroso con respecto a las iniciativas iberoamericanas de la España democrática. No ha sido nunca un participante entusiasmado, pero tampoco ha puestos palos en las ruedas para que no avanzara el carro. Al contrario que Brasil, que sí lo ha hecho en algunas ocasiones. Mi hipótesis es que Brasil entró en el juego de la política iberoamericana española para poder controlarla desde dentro, pues si se quedaba fuera no podría controlar el proceso, o ponerle obstáculos...

JMSP: Como Gran Bretaña en la Unión Europea. Relacionado con esta cuestión, ¿cómo ve Brasil las cumbres iberoamericanas? ¿En qué términos participa en ellas? ¿Va "arrastrado"? ¿Lleva una posición de "vamos a ver qué ocurre"? ¿Es testigo? ¿Quiere ser protagonista?

Bruno Ayllón Pino: Para Brasil las Cumbres Iberoamericanas no son un espacio prioritario. Para Brasil es una iniciativa diplomática de España donde merece la pena participar para no indisponer el buen estado de las relaciones bilaterales. Para España, que Brasil no participase en las cumbres iberoamericanas sería una afrenta, y la diplomacia brasileña lo leyó bien. Está en documentos de archivos que yo he consultado, y es una línea de acción diplomática muy clara. Ahora bien, dentro de esta línea diplomática hay cambios o matices en función de los diferentes gobiernos. Es cierto que, quizás, el gobierno Lula tuvo un perfil más alto, no solamente por participar en las cumbres, sino que participó en el sistema de cooperación iberoamericano, que son los casi 50-60 programas que van desde lbermúsica hasta el programa iberoamericano de fortalecimiento de la cooperación Sur-Sur, etc. Ahí la pertenencia es ad hoc, cada uno pertenece en función de los programas que le interesan, y Brasil tiene un protagonismo muy fuerte en los bancos de leche materna, un programa de cooperación técnica de Brasil que comparte en África, que es muy interesante, y es una de las de señas de identidad de la cooperación Sur-Sur brasileña. Entonces, yo creo que un análisis más en profundidad tendría que ver en qué espacio, dentro del ámbito iberoamericano, está participando Brasil. En algunos participa con interés y entusiasmo, como líder, pero a nivel político es simplemente una reunión política rutinaria, de Jefes de Estado, donde no se tratan cuestiones sustanciales. Es sintomático que, desde la cumbre de Cádiz en 2012, a la que vino Dilma Rousseff, no ha habido presencia de ningún presidente de la república en ellas. Hay que tener en cuenta que desde entonces estas cumbres pasaron de ser anuales a ser de dos en dos años, y a continuación llegó la crisis... Creo además que hay una crisis del propio formato de 
las cumbres iberoamericanas, que está agotado. En el fondo es una crisis motivada por la gran proliferación de foros latinoamericanos, que hacen que parezca que es uno más.

JMSP: Y además, ¿no tiene importancia el hecho de que participen España y Portugal, dando la sensación de que son los "padrinos" y que los demás países están "bajo las alas" de estos dos?

Bruno Ayllón Pino: No lo creo. En la Secretaría General Iberoamericana (SEGIB), que es la que gestiona las cumbres y el sistema de cooperación iberoamericano, hay una triada: está el cargo de Secretario/a General, que es electivo/a; hemos tenido un uruguayo de ascendencia asturiana, Enrique Iglesias y ahora tenemos a una costarricense, Rebeca Grynspan. El número dos es para México y el número tres es para Brasil. Portugal no aparece en los órganos de gobierno. En ese sentido, su participación es casi una aquiescencia, sin mayor implicación, ya que obviamente para ellos es más importante la CPLP portuguesa, donde sí que Brasil y Portugal son los dos motores de esa relación.

JMSP: Una pregunta sobre pasado y otra sobre futuro para acabar este apartado de relación España-Brasil. La primera pregunta sobre el pasado es que llama la atención que, aunque haya habido momentos muy relevantes en las relaciones España-Brasil, parece que haya que contar a la gente que hubo esta relación. Es decir, que se corrió aquel tupido velo, y yo tengo la experiencia propia respecto al periodo de la "Unión Ibérica" o de Brasil en la Monarquía hispánica, donde no solo hay un olvido, las fuentes son dispersas, nos enfrentamos a un territorio que historiográficamente ha sido casi olvidado, que fue interpretado por una historiografía restauracionista a partir de 1640, donde el periodo anterior se consideraba como negro... Tú hablabas en el curso también de que la presencia de los inmigrantes españoles en São Paulo y en otras grandes ciudades donde hubo muchos casi se ha diluido. Esto llama la atención, una especie de olvido de esa presencia española que, a pesar de haber sido importante históricamente, casi no aparece en la historia de Brasil. ¿Cómo ves esto? ¿Tiene qué ver con esa identidad "neoportuguesa"?

Bruno Ayllón Pino: Probablemente venga de aquello que estábamos hablando sobre Gilberto Freyre. La mayor prueba de que Brasil es un país "hispánico" es que al ser tan tenues las fronteras entre lo hispánico y lo luso, la capacidad de asimilación y desaparición es enorme. Sabes perfectamente como yo que llegan los inmigrantes, y la segunda generación ya no habla español o habla un español que es un "portuñol canalla"; y la tercera generación, pues, olvídate. Quizás responde un poco a eso. Esto no pasa con los italianos, pero claro, las distancias son diferentes, por ejemplo, en lo lingüístico. No he trabajado mucho esta cuestión, pero creo que en el caso español esa asimilación se da muy rápido, lo que hace que, incluso los que están allí, se olviden de su procedencia, también porque nunca ha habido una política, como tienen otros países, de apoyo a las comunidades que están en el exterior. Creo que es una de las grandes pérdidas que ha tenido España, no entender que el emigrante no es alguien que se va y que te libera de las "cargas" que te pueda generar en tu país, sino que el emigrante puede ser un actor activo que te puede proyectar como país, puede ser un generador de riquezas, de conexión de negocios. Ese olvidar a los emigrantes más allá de acciones puntuales de carácter asistencial, ha sido uno de los errores de la política española y, de hecho, los propios emigrantes organizaban sociedades de socorros mutuos para crear redes de solidaridad y poder enfrentar las vicisitudes de comunidades tan alejadas de su país de origen.

JMSP: Lo que yo me planteo es si esto hubiera sido posible, dado que el gobierno Vargas, poco después de la oleada migratoria, prohibió cualquier lengua que no fuera portugués; estoy hablando de las "leis de brasilidade" del Estado Novo de 1937, y además muchos de los inmigrantes españoles llegados después de la Guerra Civil eran exiliados republicanos y evidentemente el gobierno español franquista no iba a acercarse a ellos. Cuando hubo un acercamiento entre ambos países eso ya quedaba muy lejos. La pregunta final de este bloque es ¿qué se puede esperar de las relaciones España-Brasil en el contexto actual que, por un lado, obliga a estrechar relaciones en un mundo multipolar, multi-conectado, pero que, por otro, se ve condicionado por fuerzas centrífugas al haber gobiernos de distinto signo político en los dos países?

Bruno Ayllón Pino: Es difícil responder a esta pregunta, porque en el momento en el que hacemos la entrevista (mayo de 2019) no hay gobierno en España, no sabemos cuál va a ser su configuración, y en Brasil 
tenemos un gobierno que ha empezado patinando en la configuración y la base de apoyo parlamentario, fruto también de la inexperiencia, pero también de las tensiones internas que hacen que la nave zozobre apenas ha salido del puerto, con marineros que tiran para un lado, con el maquinista que tira para otro... Lo que veo es una situación de mucha incertidumbre. Evidentemente las relaciones económicas de tipo privado siguen el día a día, y me pregunto hasta qué punto un escenario de empeoramiento de ambas economías a la vez, que no es descartable, pueda afectar también a las relaciones bilaterales. Políticamente, en la hipótesis de que haya un gobierno de izquierdas, llamémoslo PSOE-Podemos y algunos nacionalistas, y que el gobierno Bolsonaro consiga terminar su mandato, creo que las relaciones políticas van a ser frías, van a ser distantes.

JMSP: ¿Esto es un retroceso respecto a lo que se había hecho antes?

Bruno Ayllón Pino: Sí. Bolsonaro es un tipo de gobernante que nunca ha tenido Brasil en estos años, primero por su desconocimiento absoluto de cómo funcionan las dinámicas de las relaciones internacionales, por su poca experiencia de vida internacional, por ser políticamente poco correcto en sus manifestaciones y en su propia forma de ser. Además, en un país donde la diplomacia presidencial es tan importante, porque no solamente es la diplomacia de los diplomáticos sino la que hace el presidente. Claro, cuando uno ve adonde han sido los primeros viajes del gobierno Bolsonaro, a Estados Unidos y a Israel, además de que tiene previsto uno a Hungría... Quiero que me cuenten los intereses de Brasil allí, ya que es en retribución a Viktor Orbán, que fue uno de los pocos que fue a la toma de posesión. Digamos que, políticamente, el gobierno de Brasil y el gobierno de España están en las antípodas, por lo que va a meter las relaciones en el congelador, por lo menos en lo político, una temporada. El problema es que, en situaciones eventuales de conflicto, al no tener esos canales de comunicación, obviamente, puede ser más complicado que en un momento de buena sintonía, pero, en fin, ahora mismo solo me atrevo a decir que hay mucha incertidumbre.

\section{Cooperación académica y científica}

ETD: En líneas generales, ya sabemos la cronología y en qué aspectos Brasil y España colaboran en términos económicos, y alguna pista sobre cuestiones migratorias. Me gustaría preguntarte a partir de cuándo las universidades españolas y brasileñas empiezan a colaborar.

Bruno Ayllón Pino: Esta relación existió desde siempre. Desde los años 1950-1960, había una política por parte de España de becas a estudiantes brasileños en España, también a estudiantes españoles para que estudiaran en Brasil. Hay alguna iniciativa de traducción de obras literarias, de obras académicas... En fin, hay alguna iniciativa. Pero, creo que es nuevamente con la llegada de las empresas españolas, por una parte, que financiaron algunas iniciativas de cooperación interuniversitaria entre España y Brasil; por otra parte, algunas fundaciones público-privadas como la Fundación Carolina. Otro ámbito sería el de las propias convocatorias de los ministerios de educación a través de programas de investigación para la formación de grupos de investigación hispano-brasileños. Esto ha funcionado relativamente bien. Quizás, en el ámbito europeo, España y Brasil no han sabido crear sinergias para presentarse a proyectos. La movilidad académica también ha funcionado un poco a base de programas específicos, como fue, en el caso de Brasil, el Ciência sem Fronteiras. Nuevamente, volviendo a la situación actual, veo una situación preocupante, ya que en la medida que muchas de estas iniciativas son proyectos cofinanciados por las dos partes, los cortes anunciados en los presupuestos de las agencias federales de fomento de la investigación como la Coordenação de Aperfeiçoamento de Pessoal de Nível Superior (CAPES) o los propios que van a sufrir las universidades federales van a impactar gravemente, por supuesto, en la financiación de proyectos, y también en el propio funcionamiento cotidiano de estas instituciones. Con lo cual, quizás se van a salvar las universidades que dependan de los recursos de los estados, que tienen poderosas fundaciones por detrás, fundaciones públicas que utilizan impuestos para financiarlas, como es el caso de la Fundação de Amparo à Pesquisa do Estado de São Paulo (FAPESP), que puede ser la vía por donde quizás se canalicen algunos de los proyectos. Pero, sin querer ser pesimista, veo que hay dificultades serias para financiar lo que está habiendo. Ya no solo hablamos de aumentar la escala de esos proyectos, con lo cual es posible 
que se siga manteniendo la relación personal que existe entre académicos de un lado y de otro, pero una relación más institucionalizada, que permita financiar proyectos de mayor envergadura y haya una movilidad más amplia y profunda entre grupos investigadores, profesores, docentes... en los dos sentidos, creo que va a ser más complicado de conseguir.

ETD: ¿Cómo ves los estudios sobre Brasil en España? Vamos a centrarnos en los centros, departamentos y líneas de investigación.

Bruno Ayllón Pino: Pues si lo vemos de manera histórica, buena parte de la acción de esos centros nace por una motivación de las embajadas de Brasil, lo que podríamos caracterizar como "el modelo brasileño". Dentro de la política exterior encontramos que la política exterior cultural, de la difusión de la cultura y de la lengua de Brasil en el mundo, forma parte del departamento cultural de Itamaraty. La queja recurrente de todos los embajadores de Brasil en España, y en donde sea, es que no había presupuesto ni para comprar libros, ni para editar. Esas restricciones que siempre ha sufrido la cultura como "prima pobre" de la acción exterior de los países, en el caso de Brasil ha sido algo atávico, siempre ha estado ahí, no ha habido manera de modificarlo. Cuando se produce un cambio es exactamente cuando Brasil experimenta en España un nuevo modelo de financiación de la acción exterior brasileña a través de la creación de la Fundación Cultural Hispano-Brasileña. Este fue un instrumento creado por diplomáticos con nombre y apellidos, y esto está escrito en algunas tesis de diplomáticos que estuvieron en Madrid cuando se creó la Fundación HispanoBrasileña, digamos que era un test de cómo se podía aprovechar la llegada de inversiones españolas a Brasil para cobrar una especie, entre comillas, esto lo digo yo, de "impuestos" a esas empresas, de modo que financiasen la difusión de la cultura brasileña en España. En este sentido, la Fundación Cultural Hispano-Brasileña respondió a ese esquema y creo que en los primeros años, no sabría decir hasta qué momento, funcionó relativamente bien. Pero creo que en un momento dado ese modelo empezó a sufrir las interferencias de lo político y problemas de gestión serios. Pienso que ese modelo se extravió y habría que repensarlo. Repensar el modelo y el compromiso de las empresas españolas, repensar qué es lo que se quiere hacer desde una fundación o un Centro de Estudios Brasileños. Hay que repensar la relación entre el mundo de la política, la embajada y el mundo de la universidad en el caso del CEB de la USAL.

ETD: Pero ¿por qué el modelo de política exterior brasileña no ha creado centros o institutos, como el caso del Cervantes, o el Goethe o la Alliance Française?

Bruno Ayllón Pino: Son las típicas cosas que carecen de sentido. Pongan los pies en la tierra: ni siquiera hay un centro de estudios brasileños en Argentina, pues el que había lo cerraron. ¿Dónde debería tener Brasil institutos de lengua portuguesa? En América Latina, es de sentido común. Además, Brasil no tiene capacidad financiera de mantener una red.

JMSP: Llama mucho la atención que Brasil, que solo tiene vecinos de habla hispana, solo recientemente haya impulsado los estudios de español y con muchas reticencias. Ni siquiera es obligatorio en las escuelas, algo que llama poderosamente la atención. No hay un país que tenga una vecindad tan importante con respecto a lenguas, y que lo descuide tanto.

Bruno Ayllón Pino: Debemos tener en cuenta que, en general, el brasileño de clase media-alta no conoce Ecuador o Chile. Prefiere irse a Europa y a Estados Unidos, por lo que prefieren aprender inglés, que es una opción muy legítima. Es la renovación del mito de la ilha Brasil, una isla, por mucho que se aprenda el español.

JMSP: Hay una vocación aislacionista de Brasil, parecida al aislacionismo de Estados Unidos, esa sensación de autosuficiencia que siempre ha tenido Brasil.

Bruno Ayllón Pino: Por supuesto, y es legítimo pero poco práctico. Es un mercado de 200 millones de habitantes. No hay que confundir la autosuficiencia en cuanto a provisión de bienes materiales o de insumos con una cuestión psicológica, de autosatisfacción. Es lo que en relaciones internacionales se llama 
"países ballena", países tan grandes que tienden a la autarquía y que es histórica, como pasa con Rusia, China, son países gigantes. El 45\% del PIB latinoamericano depende de Brasil. Y Brasil no tiene apenas conflictos fronterizos. Evidentemente la globalización y la transnacionalización de algunos fenómenos como el narcotráfico, la delincuencia organizada, etc. obligan a un mayor control de las fronteras, pero para eso está la tecnología, con radares y drones que hacen que no se necesite tener soldados a cada metro. Otra posibilidad es gestionar las relaciones en el marco de políticas regionales, a través de cuestiones comunes como gestión de aguas, control de fronteras, etc... Sin embargo, una de las primeras medidas realizadas por el gobierno Bolsonaro es que Brasil ha dejado de emitir el pasaporte con el blasón de Mercosur. Y el tema de las matrículas se acabó; ya no va a haber matrículas Mercosur. Esa tendencia es importante: ahora ya no hay una visión de la globalización benigna, liberal, que había en el gobierno FHC, que obligaba al país a abrirse mucho más en pro del sueño liberal, de una "paz perpetua" que beneficiaba a todos. En el proyecto multipolar de Lula también pasaba, ya que, para que Brasil pudiera proyectar su proyecto al exterior, la base, el locus standi, en palabras de Celso Lafer, es América Latina. Solamente si Brasil es un líder reconocido y asentado en América Latina podrá proyectarse. La lectura de Bolsonaro, sin embargo, es la contraria: alianzas con los que, como Brasil, son grandes y fuertes, es decir, Israel, Estados Unidos. Eduardo Bolsonaro, el hijo del presidente, ha declarado que Brasil debe tener armas nucleares. Brasil es firmante del tratado de no proliferación suscrito en 1998 por FHC. Es un retroceso. No quiero ser alarmista, pero cuando se desgrana medida a medida, el simbolismo que tienen... Aunque, afortunadamente, muchas de ellas son boutades que dicen en redes.

JMSP: Hay una cuestión interna de crisis económica, crisis del PT... crisis de seguridad, corrupción... pero también hay una cuestión externa. Hemos pasado del encantamiento de la globalización a la globalización del desencanto, es decir, la globalización como perspectiva ha caído en una situación de absoluto desencantamiento. En ese caldo es en el que medran muchos de los movimientos populistas, nacionalistas, de derecha y ultraderecha a que asistimos hoy, aunque también de la extrema izquierda. El nacionalismo populista no tiene ideología, puede afectar a unos y a otros. También Brasil ha entrado en esta lógica. ¿Qué te parece?

Bruno Ayllón Pino: Quizás haya una contra-reacción. Frente a ese sueño de la globalización encontramos ahora un provincianismo, el volver a lo conocido, a lo no extranjero, a lo no diferente. Poner siempre referencia de países que han fracasado. Me hace gracia cuando Brasil habla de Argentina o Venezuela como si Brasil fuera la "Suecia tropical". Es políticamente muy poco correcto que el presidente Bolsonaro, para justificar sus reformas sobre seguridad social diga: "fijese lo que les pasa a los argentinos, a la Venezuela bolivariana". Creo que estamos viendo una configuración de los descontentos de la globalización que se van aglutinando en clubs muy selectivos, son los clubs de aquellos que se identifican como similares. Esto no es espontáneo. Quiero decir que es un plan ejecutado, formulado, y que tiene muñidores. No quiero ser "conspiranoico", pero evidentemente esto no es una casualidad. Vamos a ver si Europa no se "bolsonariza", en el sentido de haber pautas mucho más nacionalistas, mucho más centradas en seguridad, en temas de rechazo al inmigrante pobre... porque a los científicos extranjeros les damos la tarjeta verde, y al que viene en patera le damos una patada.

JMSP: Has trabajado en un campo de las relaciones internacionales relacionado con la cooperación, y en concreto con la cooperación Sur-Sur. ¿Cuál es el papel de Brasil en él?

Bruno Ayllón Pino: Los investigadores siempre debemos tener en la agenda varios temas que se ponen de moda y a los cuales adscribirse para conseguir sobrevivir. En un momento dado, yo vi esa oportunidad de la cooperación Sur-Sur, el ascenso de los emergentes y del poco conocimiento que había sobre ese tema en España, en América Latina, etc. Siempre me llamaba la atención que muchas personas me decían que cómo era posible que uno de los principales expertos en cooperación Sur-Sur fuera de un país del Norte. En este caso, es por interés y por voluntad. Sabemos que eso sucede también en otras ramas de conocimiento ya que la financiación está en los países del Norte, lo que contribuye a configurar el pensamiento del Sur ya que ha sido producido por el Norte. En este sentido me interesó mucho investigar sobre la cooperación Sur-Sur, pues formaba parte del proyecto de política exterior brasileño, especialmente en los gobiernos Lula, 
ya que la cooperación Sur-Sur es la cooperación entre países en proceso de desarrollo que son diferentes, pero se reconocen como iguales e intentan cooperar en base a la horizontalidad, a la reciprocidad, a los costes compartidos y a entender que en esta cooperación lo importante es el conocimiento y no el dinero. Las técnicas y políticas públicas que se comparten son las soluciones a problemas de desarrollo que se han probado en un país y se pueden compartir y verificar si funcionan en otro país. Es decir, como modalidad de cooperación, me parece mucho más transformadora y emancipadora que la cooperación tradicional NorteSur que tiene mucho de vertical, paternalista, y donde las prioridades de los receptores son olvidadas y priman los intereses de los donantes... Como modelo, la cooperación Sur-Sur me parecía más interesante. Además, explorarla de la mano de Brasil, ya que es el único país latinoamericano, junto con Cuba, que tiene una política consistente hacia África. En este contexto, Brasil tiene una política exterior hacia África con Juscelino Kubitschek, ahí está el embrión que luego trajo un avance muy importante y retórico, poco práctico, en las políticas de João Goulart. Los militares abandonaron esta política y luego la recuperaron, de tal forma que se produjo el reconocimiento de Angola y Mozambique. Lo que cambia con el gobierno Lula es la escala, la gran expansión de las representaciones diplomáticas, lo que creo que fue muy importante, ya que le permitió a Brasil tener un peso no solamente en África sino en el sistema internacional, garantizándose votos africanos en organismos multilaterales, garantizando oportunidades de negocio... No tantas como en América Latina, pero, sin duda alguna, las grandes empresas "campeonas" brasileñas estuvieron en Angola, Mozambique, Ghana, Sudáfrica... Brasil, obviamente, no le puede hacer la competencia a China en África, pero desde luego sí a países como España. Digamos que simbólicamente, el hecho de que haya más jugadores en África representa una ventaja para la propia África, ya que tienen más opciones donde elegir, lo que aumenta su margen de maniobra. No es como antiguamente, que era Estados Unidos, Francia e Inglaterra. Ahora encontramos a los chinos, iraníes, rusos, brasileños... África como la última frontera del capitalismo me parece que es un tema muy importante, y la presencia brasileña ha hecho aportaciones interesantes. Todo esto es la cooperación Sur-Sur, un tema en el que he venido trabajando bastante tiempo, todavía trabajo, pero ya estoy de salida, creo que ya se está agotando.

JMSP: Y para concluir, ¿el gobierno actual va a acabar con esa cooperación de Brasil hacia África?

Bruno Ayllón Pino: Ya desde el gobierno Dilma Rousseff empezó a acabar. Esto es el axioma de la política de cooperación. En una crisis económica, lo primero que recortan los países es la cooperación, por una sencilla razón: la cooperación para el desarrollo es la única política pública de los estados cuyos beneficiarios no pueden sancionar o premiar la realización de esa política, ya que los beneficiarios son los ciudadanos pobres del tercer mundo, que no votan en el mundo desarrollado.

JMSP y ETD: Muchas gracias por la entrevista.

Bruno Ayllón Pino: Ha sido un placer. 
LA ACCIÓN EXTERIOR DE BRASIL A EXAMEN • JOSÉ MANUEL SANTOS PÉREZ - ELISA TAVARES DUARTE

\section{NOTAS}

${ }^{1}$ Alianza de Brasil, India, China y Sudáfrica.

${ }^{2}$ Constituido por India, Brasil y Sudáfrica.

${ }^{3}$ Comunidad de Estados Latinoamericanos y Caribeños.

${ }^{4}$ Unión de Naciones Suramericanas. 


\section{REFERENCIAS BIBLIOGRÁFICAS}

Alonso Santos, J. L. (2018). Relaciones comerciales entre España y Brasil. Las exportaciones de España en el siglo XXI. Revista de Estudios Brasileños, 5(8), 11-28.

Alonso Santos, J. L., Mendes, A. A., \& Guarnieri Ortigoza, S. A. (2017). La inversión exterior directa de España en Brasil 1996-2015. Revista de Estudios Brasileños, 4(6), 171-190.

André, B. P. (2007). De la integración deseada a la integración vivida: la experiencia de adolescentes brasileños en escuelas de Barcelona. Tesis doctoral, Universidad de Barcelona, Barcelona, España.

Ayllón Pino, B. (2004). Las relaciones entre Brasil y España ponderadas desde la perspectiva de la política exterior brasileña (1979 - 2000). Tesis doctoral, Universidad Complutense de Madrid, Madrid, España. Recuperado de [https://eprints.ucm.es/5309/1/T27854.pdf].

Ayllón Pino, B. (2007). Las relaciones hispano-brasileñas: de la mutua irrelevancia a la asociación estratégica (19452005). Salamanca: Ediciones Universidad de Salamanca.

Ayllón Pino, B. (2014). De la asociación estratégica a la crisis: las relaciones hispano-brasileñas en un contexto de cambios estructurales. Revista de Estudios Brasileños, 1(1), 25-44.

Badet Souza, M. (2011). La construcción del imaginario social de la mujer brasileña en España: análisis de la recepción mediática junto a estudiantes del $4^{\circ}$ ESO de Barcelona, Sabadell y Sitges. Tesis doctoral, Universidad Autónoma de Barcelona, Barcelona, España.

Castro Brunetto, C. J. (2016). Las devociones marianas españolas en el Brasil colonial. Revista de Estudios Brasileños, 3(4), 11-23.

Cavalcanti, L. S. (2003). Los inmigrantes brasileños en la ciudad de Barcelona: un estudio antropológico sobre sus estrategias migratorias y su vida cotidiana. Tesis doctoral, Universidad de Salamanca, Salamanca, España.

Espíndola, C. J., \& Marthins de Araujo Junior, A. (2017). Breves consideraciones sobre las relaciones comerciales entre Brasil y España. Revista de Estudios Brasileños, 4(6), 161-175.

Gambi Giménez, E. (2008). La inmigración castellana y leonesa en São Paulo, 1946-1962. Tesis doctoral, Universidad de Salamanca, Salamanca, España.

Gómez Pérez, F. J., \& Pérez Rufí, J. P. (2017). Aproximación histórica a las coproducciones hispanobrasileñas. Revista de Estudios Brasileños, 4(7), 110-121.

González Martínez, Elda E (2002). Guía de Fuentes Manuscritas para la Historia del Brasil Conservadas en España. Madrid: Fundación Mapfre Tavera.
Izepe de Souza, I. (2009). Caminhos que se cruzam: as relações históricas entre Brasil e Espanha (1930-1960). Tesis doctoral, Universidade de São Paulo, São Paulo, Brasil.

Lube Guizardi, M. (2011). Todo lo que la boca come. Flujos, rupturas y fricciones de la capoeira en Madrid. Tesis doctoral, Universidad Autónoma de Madrid, Madrid, España.

Luna De Oliveira, S. (2015). Contribución de Gilberto Freyre en la construcción de una política exterior brasileña en defensa del colonialismo portugués (19501960). Revista de Estudios Brasileños, 2(2), 101-112.

Malamud, A. (2011). A Leader Without Followers? The Growing Divergence Between the Regional and Global Performance of Brazilian Foreign Policy. Latin American Politics and Society, 53(3), 1-24.

Martín Jiménez, M. I. (2017). Patrimonio de la Humanidad Cultural y Natural en España y Brasil. Revista de Estudios Brasileños, 4(6), 127-146.

Masanet, E. (2008). De Brasil a España: un estudio sobre la migración desde la perspectiva integrada de los lugares de origen y destino. Tesis doctoral, Universidad de Alicante, Alicante, España.

Ribeiro De Oliveira, A. T. (2016). La migración de retorno a Brasil en el contexto de la crisis económica. Revista de Estudios Brasileños, 3(5), 27-41.

Santos Pérez, J. M. (2006). Brasil durante la Unión Ibérica. Algunas notas sobre el intercambio cultural entre las dos orillas del Atlántico. In VV. AA. Brasil e Espanha: diálogos culturais = España y Brasil: diálogos culturales. São Paulo: Fundação Cultural Hispano-Brasileira.

Santos Pérez, J. M., Megiani, A. P., \& Ruiz-Peinado Alonso, J. L. (Eds.). (2020). Redes y circulación en Brasil durante la Monarquía Hispánica (1580-1640). Madrid: Sílex.

Saraiva, José Flavio Sombra, (1997). O lugar da África: a dimensão atlântica da política externa brasileira, de 1946 a nossos dias. Brasília: EdUnB.

Vicente Martín, I. M. (2018). El papel de Brasil en la Historia de España y Portugal. Entrevista a Pedro Cardim. Revista de Estudios Brasileños, 5(10), 204-215.

Zamorano Blanco, V. D. (2010). De agentes del progreso a elementos del desorden: inmigrantes españoles $y$ exclusión social en Río de Janeiro (1880-1930). Tesis doctoral, Universidad de Salamanca, Salamanca, España. 